\title{
Synergistic Effects of BTK Inhibitor HM71224 and Methotrexate in a Collagen-induced Arthritis Rat Model
}

\author{
KYUNG JIN CHOI ${ }^{1,2}$, YU-YON KIM ${ }^{2}$, SUN YOUNG JANG ${ }^{2}$, YOUNG GIL AHN ${ }^{2}$, \\ KWEE HYUN SUH ${ }^{2}$, YOUNG HOON KIM ${ }^{2 *}$ and HYUNG SIK KIM ${ }^{1 *}$ \\ ${ }^{1}$ School of Pharmacy, Sungkyunkwan University, Suwon, Republic of Korea; \\ ${ }^{2}$ Hanmi Research Center, Hanmi Pharm. Co. Ltd., Gyeonggi-do, Republic of Korea
}

\begin{abstract}
Background/Aim: Using a rat model of collageninduced arthritis (CIA), we evaluated the therapeutic effects of HM71224 (BTKi), as well as the drug-drug interactions in combined therapy with methotrexate (MTX) based on both drugs' pharmacological role in immune regulation and antiinflammation. Materials and Methods: Arthritis in rats was induced using type II collagen and incomplete Freund's adjuvant. The therapeutic effects of HM71224 (alone or in combination with MTX) were evaluated by arthritis score, paw volume, body weight, and histopathological examination ( $H \& E$ and Safranin-O staining). The drug-drug interactions between HM71224 and MTX were investigated by measuring plasma, liver enzyme and creatinine levels and blood cell counts. Results: HM71224 reduced the clinical signs of arthritis, paw volume, and body weight loss in CIA rats. $E D_{50}$ and $E D_{90}$ were 1.0 and $2.5 \mathrm{mg} / \mathrm{kg}$, respectively. HM71224 combined with MTX decreased the arthritis score, bone erosion, synovitis, and cartilage degradation without apparent interaction. Conclusion: The combination of HM71224 and MTX improved the therapeutic effect with no drug-drug interactions in $R A$.
\end{abstract}

Rheumatoid arthritis (RA) is a systemic autoimmune disease characterized by synovitis and bone and cartilage damage.

This article is freely accessible online.

*These Authors contributed equally to this study.

Correspondence to: Young Hoon Kim, DVM, Ph.D., Pharmacology Team, Hanmi Research Center, 550 Dongtangiheung, Hwaseong-si, Gyeonggi-do, 18469, Republic of Korea. E-mail: yhkeem@hanmi.co.kr; Hyung Sik Kim, Ph.D., School of Pharmacy, Sungkyunkwan University, 2066, Seobu-ro, Suwon 16419, Republic of Korea.E-mail: hkims@skku.edu

Key Words: Arthritis, BTK inhibitor, collagen-induced arthritis, methotrexate, HM71224.
Many different cell types are involved in the pathogenic and pathological progression of RA. For example, B cells play several critical roles, such as autoantibody and cytokine production, antigen presentation, immune regulation, and bone homeostasis (1). Hence, rituximab, a monoclonal antiCD20 antibody that depletes B cells, has been used to treat RA (2), as well as other diseases that involve B cells (1).

Bruton's tyrosine kinase (BTK) is a non-receptor tyrosine kinase that belongs to the TEC family of kinases. During the activation of $\mathrm{B}$ cells, macrophages, and plasmacytoid dendritic cells, BTK is involved in B cell receptor (BCR)-, Fc receptor-, and Toll-like receptor-mediated signaling (3-5). This kinase is also associated with monocyte-derived osteoclast formation (6). Therefore, BTK cellular expression and function have been implicated as potential drug targets for treating autoimmune diseases, including RA. Furthermore, BTK inhibitors have demonstrated their therapeutic potential in rodent arthritis models (7-9). We previously reported that HM71224, an irreversible and selective BTK inhibitor, improves the clinical signs of arthritis, decreases the production of autoantibodies and cytokines, and reduces the damage to bone and cartilage in a collagen-induced arthritis (CIA) mouse model (8).

Methotrexate (MTX) is one of the disease-modifying antirheumatic drugs (DMARDs) used for the treatment of RA. MTX inhibits T cell activation, downregulates B cell (10), and modulates receptor activator of the NF-kB ligand (RANKL) expression (11), which are involved in the pathogenesis and progression of RA. In adult RA patients, MTX monotherapy is recommended as first-line therapy; furthermore, it is also recommended as a co-therapy when using either biologic DMARDs or tofacitinib (12). Therefore, a comparison of risks and benefits of MTX co-administration with any novel therapeutic is essential, because MTX-based treatments form the core treatment for patients with RA.

In this study, we evaluated the advantages and disadvantages of HM71224 and MTX combination therapy. We established the effective dose (ED) of HM71224 in the 
CIA rat model and then investigated the anti-arthritic effects and drug-drug interactions of HM71224 and MTX used as a combination therapy.

\section{Materials and Methods}

Reagents. HM71224 was synthesized by the Hanmi Research Center (Hwaseong, Republic of Korea). MTX was purchased from SigmaAldrich (St. Louis, MO, USA). Immunization grade bovine type II collagen was supplied by Chondrex, Inc. (Redmond, WA, USA). Incomplete Freund's adjuvant (IFA), dimethyl sulfoxide (DMSO), and Tween ${ }^{\circledR} 20$ were purchased by Sigma-Aldrich. Sodium heparin and blood collection tubes containing dipotassium ethylenediaminetetraacetic acid (EDTA) salt were purchased from Choongwae Pharmaceutical Co., Ltd. (Seoul, Republic of Korea) and BD Bioscience (San Jose, CA, USA), respectively.

Animals. Male Lewis rats aged 6 weeks (Charles River Japan) were maintained in a controlled environment with $22 \pm 2^{\circ} \mathrm{C}$ temperature, $50 \pm 20 \%$ humidity, and a $12 \mathrm{~h}$ light/dark cycle. Rats were fed standard pelleted food (Picolab Rodent Diet 5053, St. Louis, MO, USA) and water ad libitum during study period. All animal experimental procedures were approved by the Institutional Animal Care and Use Committee of the Hanmi Research Center and were performed in accordance with approved guidelines.

Induction of CIA in rats. Lewis rats were immunized with $0.6 \mathrm{ml}$ of bovine type II collagen and IFA emulsion via intradermal injection at the base of the tail. A booster injection was given on day 7 by injecting $0.3 \mathrm{ml}$ of the emulsion in the same manner.

Treatments. Two independent sets of experiments using the CIA rat model were performed. In the first set of experiments ( $n=7 /$ group), to evaluate the therapeutic efficacy of the HM71224 monotherapy, it was orally administered at $0.3,1$, or $3 \mathrm{mg} / \mathrm{kg}$ once daily for 9 days. In the second set of experiments ( $n=5 /$ group), to determine the combined effects of HM71224 and MTX, rats were orally administered HM71224 (1 mg/kg, once daily), MTX (1 mg/kg, twice weekly), or HM71224 (1 mg/kg, once daily) plus MTX (1 $\mathrm{mg} / \mathrm{kg}$, twice weekly) for 10 days. In combination groups, HM71224 was first administered orally, followed 5min later by oral administration of MTX. Both sets of experiments, the treatments were initiated 6 days after the booster immunization. HM71224 was dissolved in water containing 3.3\% DMSO and $1.7 \%$ Tween ${ }^{\circledR} 20$; MTX was dissolved in $10 \%$ DMSO in water.

Clinical assessment of arthritis. The severity of arthritis was evaluated by assessing the arthritis score, body weight loss, and paw volume. The arthritis score was determined by grading each paw from 0 to $4(0$, normal; 1 , mild but definite redness and swelling of the ankle or apparent redness and swelling limited to individual digits, regardless of the number of affected digits; 2, moderate redness and swelling of the ankle; 3 , redness and swelling of the entire paw, including digits; 4, maximally inflamed limb with involvement of multiple joints) and then expressed as the sum of all four paw scores. The arthritis score and body weight were measured three times a week. For the combined drug experiments, the volume of two hind paws was measured using a plethysmometer (Ugo Basile, Italy) 9 days after the first administration of the drugs.
Blood chemistry and hematology. To evaluate the effects of combination therapy, EDTA-anticoagulated blood and serum were collected on day 9. Complete blood cell counts (CBCs) were obtained using an ADVIA120 automatic blood analyzer (Siemens, Germany), and serum levels of aspartate aminotransferase (AST), alanine aminotransferase (ALT), and creatinine were measured using a Hitachi 7020 automatic chemical analyzer (Hitachi, Japan).

Histopathological assessment. The hind ankle joints of each rat were fixed with $10 \%$ neutral-buffered formalin, decalcified with $5 \%$ formic acid, and embedded in paraffin. The sections were stained with hematoxylin and eosin (H\&E) and Safranin-O to identify damage to bone and cartilage, respectively. The histopathological score was evaluated microscopically in a blinded manner and expressed as the sum of the scores of the two joints. The arthritis score was evaluated on a scale of 0 to 4 : 0 , normal; 1 , hyperplasia of the synovial membrane and the presence of polymorphonuclear infiltrates; 2 , pannus and fibrous tissue formation and focal subchondral bone erosion; 3, articular cartilage destruction and bone erosion; 4, extensive articular cartilage destruction and bone erosion. The bone erosion score was graded from 0 to 4 for severity as follows: 0 , normal; 1 , focal subchondral erosion; 2 , multiple subchondral erosion; 3 , multiple subchondral erosions and focal erosion of the talus; 4, multiple erosion of the tarsal and metatarsal bones. Synovitis was scored from 0 to 4: 0 , normal; 1 , mild synovial hypertrophy ( $<5$ cell layers) with few inflammatory cells; 2 , moderate synovial hypertrophy ( $<20$ cell layers) with the accumulation of inflammatory cells into intrasynovial cysts; 3 , pannus, and fibrous tissue formation, abscess, and interstitial edema; 4, pannus, and fibrous tissue formation, abscess, and interstitial edema on both sides of the ankle joint. Cartilage degradation was scored semiquantitatively from 0 to 4: 0 , intact; 1 , minor depletion $(<10 \%) ; 2$, moderate depletion $(10 \%$ $50 \%)$; 3 , high depletion $(50 \%-80 \%)$; 4 , severe depletion $(80 \%-100 \%)$.

Pharmacokinetics. To evaluate the effect of HM71224 and MTX combination, blood from the jugular vein was collected into the tubes containing heparin $(1000 \mathrm{IU} / \mathrm{ml})$ at $0,0.5,1,2,4,7$, and $24 \mathrm{~h}$ after the final drug administration on day 11. Plasma was obtained by centrifugation at $12,000 \mathrm{rpm}$ for $2 \mathrm{~min}$, and stored at $-80^{\circ} \mathrm{C}$ until analysis. Pharmacokinetic parameters were calculated from plasma concentration-time data by a non-compartmental method using Phoenix ${ }^{\mathrm{TM}}$ WinNonlin ${ }^{\circledR} 6.1$ (Pharsight, Princeton, NJ, USA). The peak plasma concentration $\left(\mathrm{C}_{\max }\right)$ and corresponding time $\left(\mathrm{T}_{\max }\right)$ were obtained directly from the raw data. The area under the plasma concentration versus time curve $\left(\mathrm{AUC}_{\text {last }}\right)$ was obtained from the linear-log trapezoidal summation.

LC-MS/MS analysis. The plasma sample analysis was performed by using LC-MS/MS system with Agilent ${ }^{\mathrm{TM}} 1200$ series (Santa Clara, CA, USA) and API5000 (Applied Biosystems/MDS SCIEX, Canada). The sample was separated on Luna Phenyl Hexyl column (2.0 X $150 \mathrm{~mm}, 5 \mu \mathrm{m}$, Phenomenex, USA) using elution with an isocratic mobile phase of $70 \%$ ammonium acetate containing $0.1 \%$ formic acid $/ 30 \%$ acetonitrile $(\mathrm{v} / \mathrm{v})$ at $35^{\circ} \mathrm{C}$. The flow rate of the mobile phase was $0.3 \mathrm{ml} / \mathrm{min}$, and the injection volume was $3 \mu \mathrm{L}$. The precursor ion and product ion were $\mathrm{m} / \mathrm{z} 471.1 \rightarrow 416.1$ for $\mathrm{HM} 71224, \mathrm{~m} / \mathrm{z} 455.2 \rightarrow 308.0$ for methotrexate and $\mathrm{m} / \mathrm{z} 521.0 \rightarrow$ 485.0 for a structurally related Hanmi compound as internal standard (IS), respectively. The optimal MS parameters were defined as follows: the declustering potential (V) were set at $111 \mathrm{~V}$ 

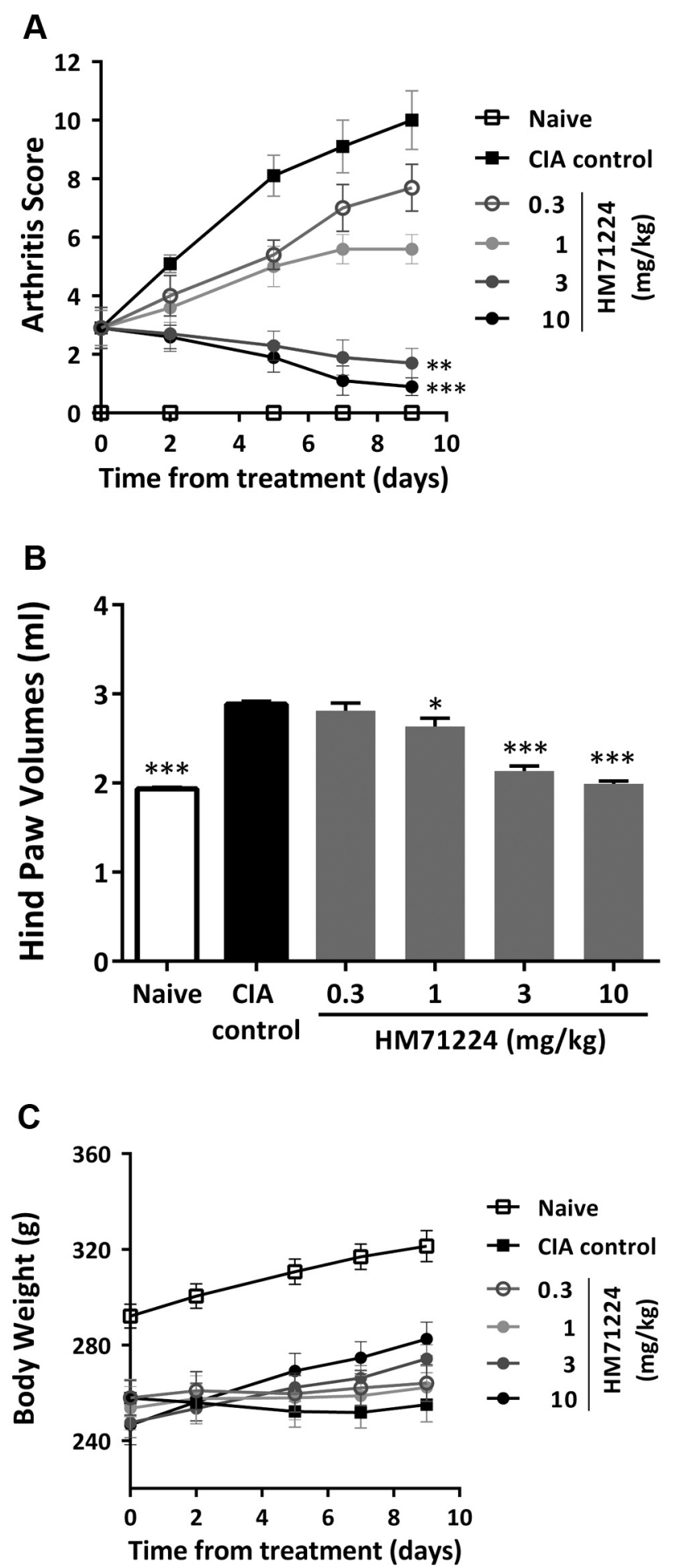

Figure 1. Effect of HM71224 on the development of arthritis in the CIA rat model. The treatment of HM71224 was initiated at the mean arthritis score of $2.9(n=7 /$ group $)$. Arthritis score and body weight were evaluated three times per week. (A) Arthritis score; (B) hind paw volume; and $(C)$ body weight during the course of the disease. Data are presented as the mean \pm SEM. $* p<0.05$, **p $p<0.01$, and $* * * p<0.001$ vs. vehicle-treated CIA rats (using the Kruskal-Wallis test).
A

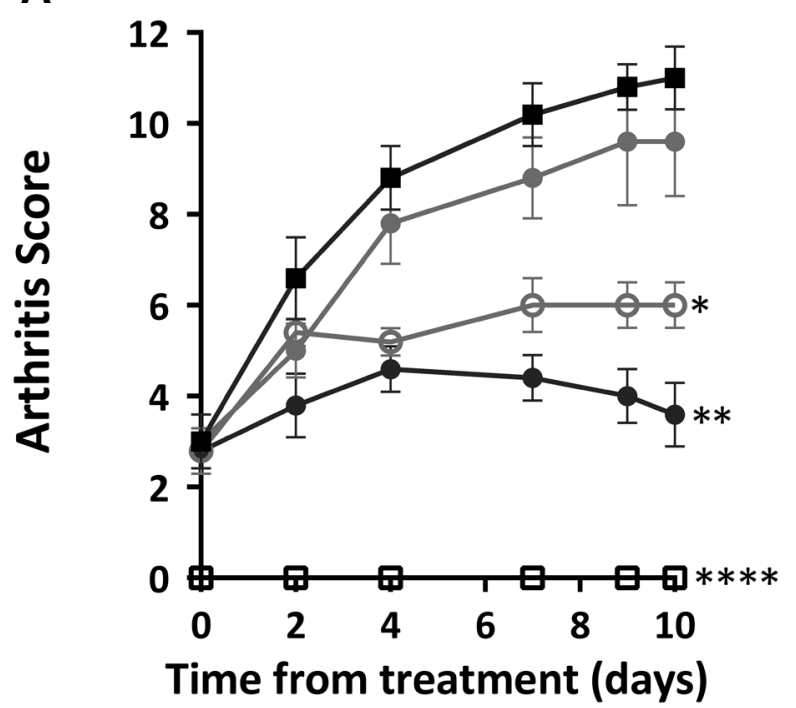

B
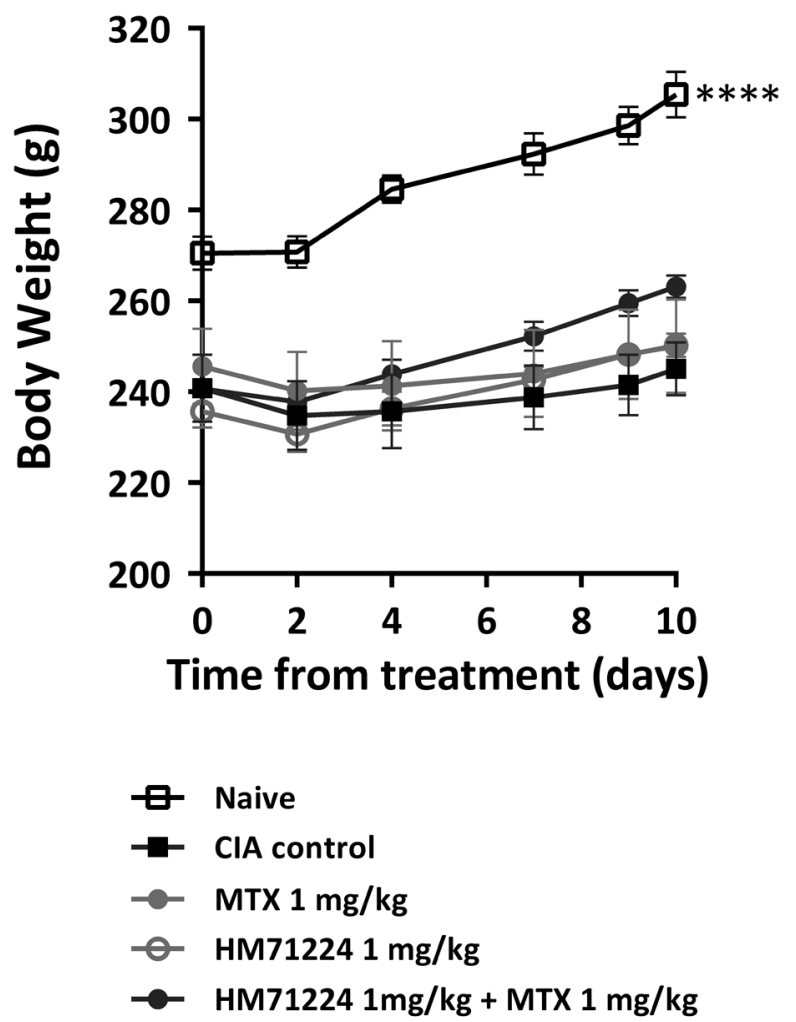

Figure 2. Effects of HM71224 and MTX combination on disease progression in the CIA rat model. HM71224 and MTX single or combined treatments were initiated 6 days after the booster immunization at the mean arthritis score of 2.9 for each group ( $n=5 /$ group) and continued for 10 days. (A) Arthritis score; (B) body weight during the course of the disease. Data are presented as the mean \pm SEM. $* p<0.05, * * p<0.01$, and $* * * * p<0.0001 v s$. vehicle-treated CIA rats (using ANOVA). 

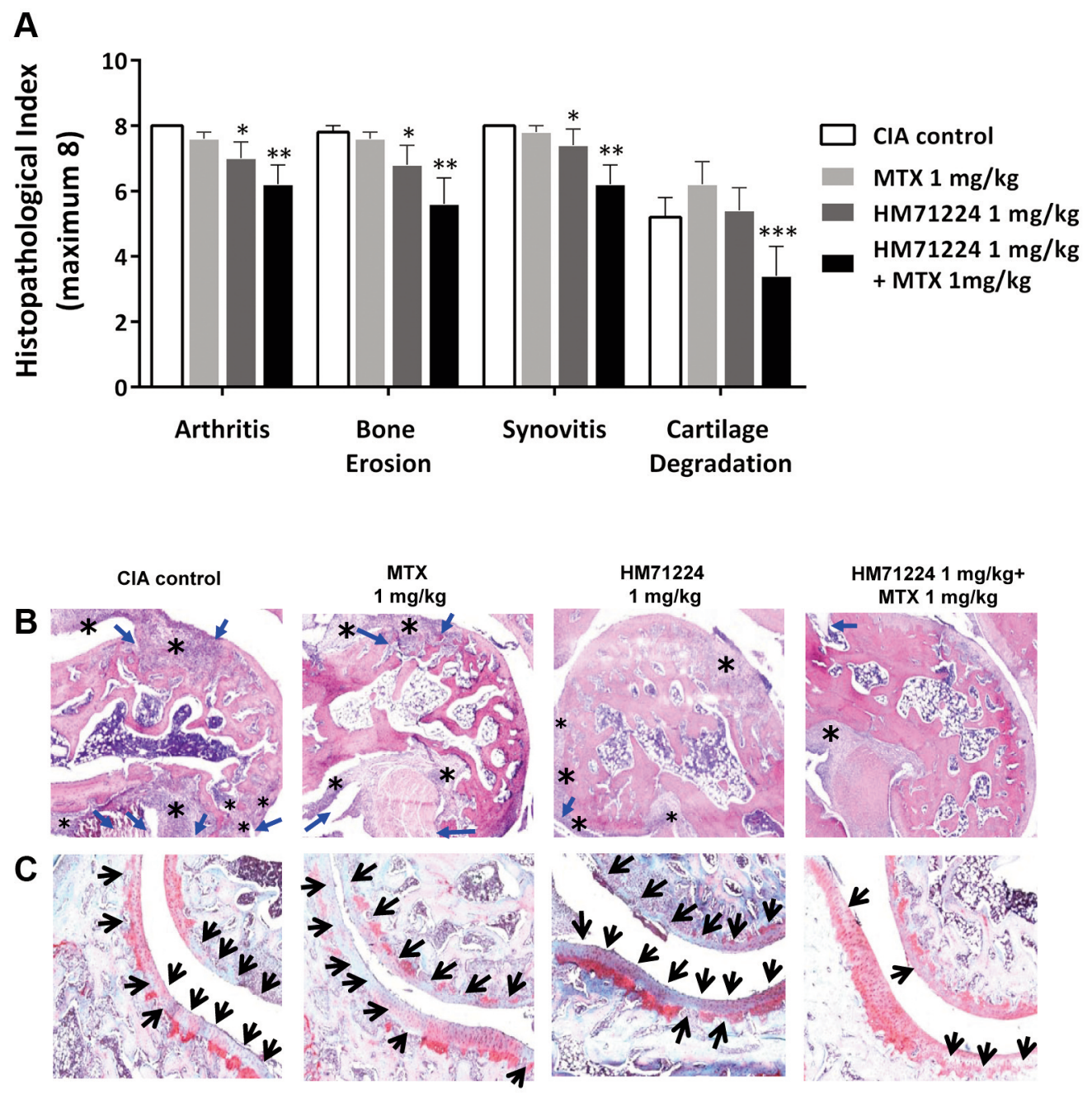

Figure 3. Histopathological assessment of CIA rat ankle joints treated with single and combination therapy of HM71224 and MTX. Histopathological evaluation of both hind ankle joints was conducted 10 days after the first administration. Indices of arthritis, bone erosion, and synovitis were evaluated using $H \& E$ staining, and cartilage degradation index was assessed using Safranin-O staining. (A) Histopathological index was expressed as the sum of scores from both hind ankle joints and included the arthritis score, bone erosion score, synovitis score, and cartilage destruction score. $(B-C)$ Histological staining of the ankle joints (100x magnification), representative $H \& E(B)$ and Safranin-O $(C)$ stained images. Data are presented as the mean $\pm S E M . * p<0.05, * * p<0.01$, and ${ }^{* * *} p<0.001$ vs. vehicle-treated CIA rats (using ANOVA). Bone erosion (blue arrows) was scored a subchondral and bone destruction and synovitis (*) was quantified degree of inflammation (H\&E). Cartilage damage (black arrows) was semi-quantitatively scored as an intensity of Safranin-O staining (red).

for HM71224, 86V for methotrexate and 191V for IS; the collision energies were set at 43V for HM71224, 29V for methotrexate and $37 \mathrm{~V}$ for IS. AB SCIEX Analyst 1.6.3 software (Canada) was used for data acquisition.

Statistical analyses. Except where indicated otherwise, the data are expressed as the mean \pm standard error of the mean (SEM). Differences between the mean values of the groups were compared using a parametric one-way ANOVA test or non-parametric Kruskal-Wallis test using the Prism 5.0 software (GraphPad, La Jolla, CA, USA). Statistical significance was set at $p<0.05$. ED was also calculated using the Prism 5.0 software.

\section{Results}

Effects of HM71224 on the development of arthritis in the CIA rat model. First, we examined whether HM71224 treatment had any effects on body weight loss and the clinical signs of arthritis in the CIA rat model. Our results showed that HM71224 reduced paw volume and the signs of arthritis, such as increased edema and erythema of ankle joints, in a dosedependent manner. Compared to that of the CIA control, the arthritis score (Figure 1A) of the rats treated with $3 \mathrm{mg} / \mathrm{kg}$ and 
$10 \mathrm{mg} / \mathrm{kg}$ doses $(p<0.01$ at $3 \mathrm{mg} / \mathrm{kg}$ and $p<0.001$ at $10 \mathrm{mg} / \mathrm{kg}$ ) was significantly reduced. Similar results were observed for hind paw edema $(p<0.001$ for both 3 and $10 \mathrm{mg} / \mathrm{kg}$ doses $v s$. the CIA control) (Figure 1B). HM71224 treatment also prevented body weight loss (Figure 1C). The calculated $\mathrm{ED}_{50}$ and $\mathrm{ED}_{90}$ values were 1.0 and $2.5 \mathrm{mg} / \mathrm{kg}$, respectively.

Combined effects of HM71224 and MTX on CIA disease progression. Next, we evaluated the combined effects of HM71224 and MTX using the CIA rat model. As expected, the vehicle-treated rats developed severe arthritis, including swollen and red paws, whereas MTX or HM71224 treatments resulted in partial reduction of the arthritis score (Figure 2A, $p<0.05 v s$. the CIA control group). The combination of HM71224 with MTX markedly decreased the severity of arthritis (Figure 2A, $p<0.01 v s$. the CIA control group); however, it did not have any effect on body weight loss (Figure 2B). Furthermore, the combination of HM71224 with MTX showed synergistic inhibition of histopathological parameters, such as bone erosion, synovial inflammation, edema, synovial hypertrophy, synovial hyperplasia, pannus, fibrous tissue formation, and cartilage degradation (Figure 3A-C).

Drug-drug interactions by co-administration of HM71224 and MTX. To investigate drug-drug interactions, the plasma levels of HM71224 and MTX were examined and the plasma concentration-time curves are shown in Figure 4. As shown in Table I, there were no significant differences in plasma parameters, such as $\mathrm{AUC}_{\text {last }}$ and $\mathrm{C}_{\text {max }}$, between HM71224 and MTX alone and HM71224 in combination with MTX $(p>0.05)$. Although the $\mathrm{C}_{\max }$ of MTX alone and that of MTX in combination with HM71224 showed a 1.5-fold difference, the $\mathrm{AUC}_{\text {last }}$ values were similar in both groups.

To investigate the effect of HM71224 and MTX combination treatment on hepatic, renal, and hematological parameters, serum AST, ALT, creatinine levels, as well as complete blood cell counts (CBC), were measured. Our results showed that the combination of HM71224 and MTX did not increase liver enzymes and kidney function parameters or cause any hematological abnormalities (Table II).

\section{Discussion}

We previously reported that selective and irreversible BTK inhibition by HM71224 suppressed human B cell activation, cytokine secretion, and osteoclast formation in vitro; furthermore, HM71224 effectively ameliorated experimental arthritis by suppressing cytokines and autoantibodies in a CIA mouse model (8). In this study, we showed that, similarly to the findings of our previous mouse experiments, HM71224 treatment decreased experimental arthritis parameters in the CIA rat model in a dose-dependent manner. Both MTX and HM71224 modulate B cells, cytokines, and
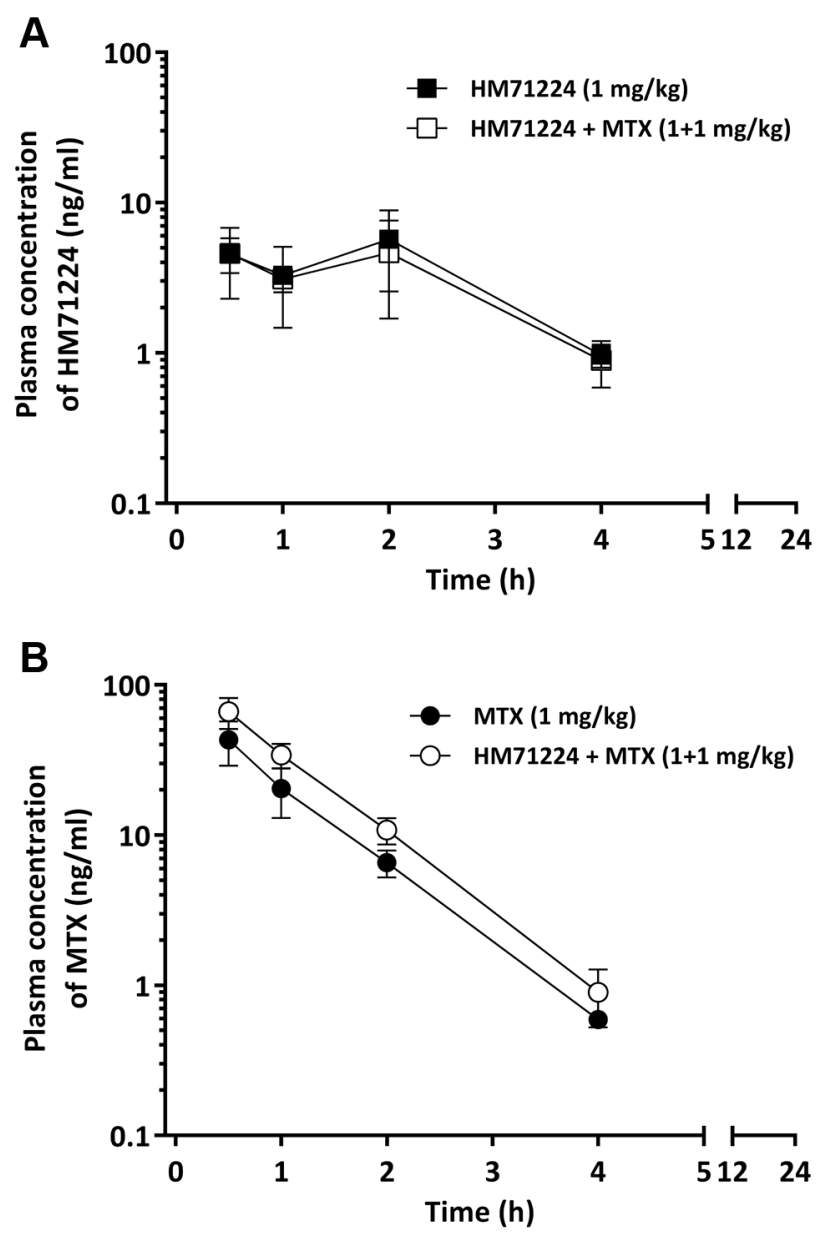

Figure 4. Mean plasma concentration-time curves of HM71224 (A) and MTX (B) after repeated dosing of HM71224 and MTX single or combination for 10 days $(n=5 /$ group $)$. Data are presented as the mean $\pm S D$.

osteoclastogenesis during RA; however, these drugs act via different mechanisms $(8,10,11,13)$. For example, MTX affects $\mathrm{B}$ cell proliferation by reducing cell division through inhibition of folic acid metabolism (10), whereas HM71224 suppresses B cells by blocking BCR signaling (8). Furthermore, MTX reduces bone loss via inhibition of RANKL production by fibroblasts (11) whereas HM71224 suppresses osteoclastogenesis directly (8). Moreover, MTX directly inhibits the activation of T cells (10) whereas PF-06250112, another BTK inhibitor, reduces the number of activated CD4+ $\mathrm{T}$ cells indirectly via BTK inhibition in other cell types (15). Hence, these drugs complement each other by inhibiting B cells, $\mathrm{T}$ cells, and osteoclastogenesis via different mechanisms of action during RA treatment. Therefore, we hypothesized that the combination of HM71224 with MTX would exert synergistic therapeutic effects by modulating the activation of $\mathrm{B}$ cells and $\mathrm{T}$ cells, as well as osteoclasts. Our results 
in vivo $35: 3245-3251(2021)$

Table I. Pharmacokinetic parameters in single and combination therapy of HM71224 and MTX (n=5/group) after repeated administration for 10 days.

\begin{tabular}{lcccc}
\hline & HM71224 $(1 \mathrm{mg} / \mathrm{kg})$ & HM71224 $(1 \mathrm{mg} / \mathrm{kg})+\mathrm{MTX}(1 \mathrm{mg} / \mathrm{kg})$ & $\mathrm{MTX}(1 \mathrm{mg} / \mathrm{kg})$ \\
\cline { 3 - 4 } Analyte & HM71224 & HM71224 & MTX & MTX \\
\hline $\mathrm{AUC}_{\text {last }}(\mathrm{ng} \cdot \mathrm{h} / \mathrm{ml})$ & $12.9 \pm 4.0$ & $11.4 \pm 4.1$ & $69.0 \pm 13.6$ & $61.9 \pm 42.7$ \\
$\mathrm{C}_{\max }(\mathrm{ng} / \mathrm{ml})$ & $6.7 \pm 2.8$ & $5.6 \pm 2.7$ & $66.4 \pm 15.5$ & $43.0 \pm 14.0$ \\
$\mathrm{~T}_{\max }(\mathrm{h})$ & $2.0(0.5,2.0)$ & $0.5(0.5,2.0)$ & $0.5(-)$ & $0.5(-)$ \\
\hline
\end{tabular}

Data are presented as the mean $\pm \mathrm{SD} . \mathrm{T}_{\max }$ is presented as median (min, max). $\mathrm{AUC}_{\text {last }}$, Area under the curve from the time of dosing to the time of last quantifiable concentration; $\mathrm{C}_{\max }$, Maximum observed concentration occurring at $\mathrm{T}_{\max } ; \mathrm{T}_{\max }$, Time of maximum observed concentration.

Table II. Effects of HM71224 and MTX combination on hepatic, renal, and hematological parameters.

\begin{tabular}{|c|c|c|c|c|c|c|c|}
\hline & \multicolumn{2}{|c|}{ Liver enzymes } & \multirow{2}{*}{$\begin{array}{l}\text { Kidney function } \\
\text { Creatinine } \\
\text { (mg/dl) }\end{array}$} & \multicolumn{4}{|c|}{ Complete blood cell counts } \\
\hline & $\begin{array}{l}\mathrm{AST} \\
(\mathrm{IU} / \mathrm{l})\end{array}$ & $\begin{array}{l}\text { ALT } \\
\text { (IU/1) }\end{array}$ & & $\begin{array}{c}\text { RBC } \\
\left(\times 10^{6 / \mu 1}\right)\end{array}$ & $\begin{array}{l}\text { Hemoglobin } \\
(\mathrm{g} / \mathrm{dl})\end{array}$ & $\begin{array}{c}\text { WBC } \\
\left(\times 10^{3} / \mu \mathrm{l}\right)\end{array}$ & $\begin{array}{l}\text { Platelets } \\
\left(\times 10^{3} / \mu \mathrm{l}\right)\end{array}$ \\
\hline Naïve & $96.4 \pm 4.1$ & $41.2 \pm 5.1$ & $0.4 \pm 0.0$ & $8.48 \pm 0.13$ & $14.2 \pm 0.1$ & $6.30 \pm 1.67$ & $767 \pm 37$ \\
\hline CIA control & $113.3 \pm 8.2$ & $36.1 \pm 3.2$ & $0.4 \pm 0.0$ & $8.71 \pm 0.20$ & $13.9 \pm 0.3$ & $7.12 \pm 0.96$ & $1,043 \pm 60$ \\
\hline $\mathrm{HM} 712241 \mathrm{mg} / \mathrm{kg}$ & $90.5 \pm 3.4$ & $39.1 \pm 2.0$ & $0.4 \pm 0.0$ & $8.59 \pm 0.19$ & $13.7 \pm 0.4$ & $5.61 \pm 2.30$ & $924 \pm 70$ \\
\hline MTX $1 \mathrm{mg} / \mathrm{kg}$ & $102.9 \pm 3.5$ & $38.4 \pm 4.0$ & $0.4 \pm 0.0$ & $8.60 \pm 0.29$ & $13.9 \pm 0.4$ & $6.47 \pm 0.66$ & $930 \pm 101$ \\
\hline HM71224 1 mg/kg+MTX 1 mg/kg & $86.4 \pm 2.7$ & $38.3 \pm 1.9$ & $0.4 \pm 0.0$ & $8.46 \pm 0.39$ & $13.9 \pm 0.5$ & $6.05 \pm 1.44$ & $916 \pm 74$ \\
\hline
\end{tabular}

AST: Aspartate transaminase; ALT: alanine transaminase; CIA: collagen-induced arthritis; RBC: red blood cells; WBC: white blood cells.

demonstrate that the combined treatment using the low dose of HM71224 and MTX effectively suppresses both disease activity, including the erythema and edema of ankle joints, and structural (bone and cartilage) damage.

It has been previously reported that co-administration of some drugs with MTX has caused variations in the pharmacokinetic parameters of MTX. For example, nonsteroidal anti-inflammatory drugs, including ibuprofen, naproxen, salicylates, and cyclosporine, reduced creatinine and MTX clearance, leading to a significant increase in MTX plasma levels $(13,16)$; chloroquine decreased the bioavailability of MTX by approximately 50\% (17). Therefore, these drug-drug interactions have practical implications for both the safety and efficacy of these drugs as a combination therapy with MTX. In this study, the coadministration of HM71224 and MTX at the effective dose did not affect the pharmacokinetic parameters and serum creatinine levels (Table I and Table II), confirming the safety of HM71224 and MTX combination therapy.

Gastrointestinal, hepatic, and hematological toxicities are commonly observed after treatment of RA and other autoimmune diseases with MTX (18). Moreover, some drugs interact with MTX to produce additive hepatotoxicity and hematotoxicity (19). Hence, prescribing guidelines should recommend the assessment of liver enzymes and CBCs prior to initiation of MTX, as well as at regular intervals for the duration of the therapy $(20,21)$. If co-administration of MTX leads to abnormal liver enzyme levels and hematological parameters, the combination regimen should not be used as a treatment. In this study, we showed that the combination of HM71224 and MTX at the effective dose did not affect liver enzyme levels or blood cell counts (Table II).

\section{Conclusion}

Using an inflammatory arthritis animal model, this study demonstrated that the combination of HM71224 with MTX showed effective and safe therapeutic effects with no apparent drug-drug interactions. Our results indicate that the combined HM71224/MTX therapy could be used as another option for treating patients with RA.

\section{Conflicts of Interest}

The Authors declare that we have no commercial or associative conflicts of interest.

\section{Authors' Contributions}

KJC and YYK conducted most of the experiments and drafted the manuscript. KHS, YGA and SYJ made substantial contributions to 
the analysis and interpretation of data. YHK and HSK conceived the study, analyzed, interpreted data and involved in drafting the manuscript.

\section{References}

1 Bugatti S, Vitolo B, Caporali R, Montecucco C and Manzo A: $B$ cells in rheumatoid arthritis: from pathogenic players to disease biomarkers. Biomed Res Int 2014: 681678, 2014. PMID: 24877127. DOI: $10.1155 / 2014 / 681678$

2 Mok CC: Rituximab for the treatment of rheumatoid arthritis: an update. Drug Des Devel Ther 8: 87-100, 2013. PMID: 24403823. DOI: $10.2147 /$ DDDT.S41645

3 Satterthwaite $\mathrm{AB}$ and Witte ON: The role of Bruton's tyrosine kinase in B-cell development and function: a genetic perspective. Immunol Rev 175: 120-127, 2000. PMID: 10933597.

4 Jongstra-Bilen J, Puig Cano A, Hasija M, Xiao H, Smith CI and Cybulsky MI: Dual functions of Bruton's tyrosine kinase and Tec kinase during Fcgamma receptor-induced signaling and phagocytosis. J Immunol 181(1): 288-298, 2008. PMID: 18566394. DOI: $10.4049 /$ jimmunol.181.1.288

5 Lee KG, Xu S, Wong ET, Tergaonkar V and Lam KP: Bruton's tyrosine kinase separately regulates NFkappaB p65RelA activation and cytokine interleukin (IL)-10/IL-12 production in TLR9-stimulated B Cells. J Biol Chem 283(17): 11189-11198, 2008. PMID: 18276597 . DOI: 10.1074/jbc.M708516200

6 Shinohara M, Chang BY, Buggy JJ, Nagai Y, Kodama T, Asahara $\mathrm{H}$ and Takayanagi $\mathrm{H}$ : The orally available Btk inhibitor ibrutinib (PCI-32765) protects against osteoclast-mediated bone loss. Bone 60: 8-15, 2014. PMID: 24316417. DOI: 10.1016/j.bone.2013.11.025

7 Akinleye A, Chen Y, Mukhi N, Song Y and Liu D: Ibrutinib and novel BTK inhibitors in clinical development. J Hematol Oncol 6: 59, 2013. PMID: 23958373. DOI: 10.1186/1756-8722-6-59

8 Park JK, Byun JY, Park JA, Kim YY, Lee YJ, Oh JI, Jang SY, Kim YH, Song YW, Son J, Suh KH, Lee YM and Lee EB: HM71224, a novel Bruton's tyrosine kinase inhibitor, suppresses $\mathrm{B}$ cell and monocyte activation and ameliorates arthritis in a mouse model: a potential drug for rheumatoid arthritis. Arthritis Res Ther 18: 91, 2016. PMID: 27090981. DOI: 10.1186/s13075016-0988-Z

9 Xu D, Kim Y, Postelnek J, Vu MD, Hu DQ, Liao C, Bradshaw M, Hsu J, Zhang J, Pashine A, Srinivasan D, Woods J, Levin A, O'Mahony A, Owens TD, Lou Y, Hill RJ, Narula S, DeMartino J and Fine JS: RN486, a selective Bruton's tyrosine kinase inhibitor, abrogates immune hypersensitivity responses and arthritis in rodents. J Pharmacol Exp Ther 341(1): 90-103, 2012. PMID: 22228807. DOI: 10.1124/jpet.111.187740

10 Wessels JA, Huizinga TW and Guchelaar HJ: Recent insights in the pharmacological actions of methotrexate in the treatment of rheumatoid arthritis. Rheumatology (Oxford) 47(3): 249-255, 2008. PMID: 18045808. DOI: 10.1093/rheumatology/kem279

11 Revu S, Neregård P, af Klint E, Korotkova M and Catrina AI: Synovial membrane immunohistology in early-untreated rheumatoid arthritis reveals high expression of catabolic bone markers that is modulated by methotrexate. Arthritis Res Ther 15(6): R205, 2013. PMID: 24295447. DOI: 10.1186/ar4398

12 Hazlewood GS, Barnabe C, Tomlinson G, Marshall D, Devoe DJ and Bombardier C: Methotrexate monotherapy and methotrexate combination therapy with traditional and biologic disease modifying anti-rheumatic drugs for rheumatoid arthritis: A network meta-analysis. Cochrane Database Syst Rev (8): CD010227, 2016. PMID: 27571502. DOI: 10.1002/14651858.CD010227.pub2

$13 \mathrm{Rau} \mathrm{R}$ and Herborn G: Benefit and risk of methotrexate treatment in rheumatoid arthritis. Clin Exp Rheumatol 22(5 Suppl 35): S83-S94, 2004. PMID: 15552520.

14 Brody M, Böhm I and Bauer R: Mechanism of action of methotrexate: experimental evidence that methotrexate blocks the binding of interleukin 1 beta to the interleukin 1 receptor on target cells. Eur J Clin Chem Clin Biochem 31(10): 667-674, 1993. PMID: 8292668. DOI: 10.1515/cclm.1993.31.10.667

15 Rankin AL, Seth N, Keegan S, Andreyeva T, Cook TA, Edmonds J, Mathialagan N, Benson MJ, Syed J, Zhan Y, Benoit SE, Miyashiro JS, Wood N, Mohan S, Peeva E, Ramaiah SK, Messing D, Homer BL, Dunussi-Joannopoulos K, NickersonNutter CL, Schnute ME and Douhan J 3rd: Selective inhibition of BTK prevents murine lupus and antibody-mediated glomerulonephritis. J Immunol 191(9): 4540-4550, 2013. PMID: 24068666. DOI: 10.4049/jimmunol.1301553

16 Fox RI, Morgan SL, Smith HT, Robbins BA, Choc MG and Baggott JE: Combined oral cyclosporin and methotrexate therapy in patients with rheumatoid arthritis elevates methotrexate levels and reduces 7-hydroxymethotrexate levels when compared with methotrexate alone. Rheumatology (Oxford) 42(8): 989-994, 2003. PMID: 12730515. DOI: 10.1093/rheumatology/keg277

17 Seideman P, Albertioni F, Beck O, Eksborg S and Peterson C: Chloroquine reduces the bioavailability of methotrexate in patients with rheumatoid arthritis. A possible mechanism of reduced hepatotoxicity. Arthritis Rheum 37(6): 830-833, 1994. PMID: 8003056. DOI: 10.1002/art.1780370609

18 Salliot C and van der Heijde D: Long-term safety of methotrexate monotherapy in patients with rheumatoid arthritis: a systematic literature research. Ann Rheum Dis 68(7): 11001104, 2009. PMID: 19060002. DOI: 10.1136/ard.2008.093690

19 Cudmore J, Seftel M, Sisler J and Zarychanski R: Methotrexate and trimethoprim-sulfamethoxazole: toxicity from this combination continues to occur. Can Fam Physician 60(1): 5356, 2014. PMID: 24452563.

20 Saag KG, Teng GG, Patkar NM, Anuntiyo J, Finney C, Curtis JR, Paulus HE, Mudano A, Pisu M, Elkins-Melton M, Outman R, Allison JJ, Suarez Almazor M, Bridges SL Jr, Chatham WW, Hochberg M, MacLean C, Mikuls T, Moreland LW, O'Dell J, Turkiewicz AM, Furst DE and American College of Rheumatology: American College of Rheumatology 2008 recommendations for the use of nonbiologic and biologic disease-modifying antirheumatic drugs in rheumatoid arthritis. Arthritis Rheum 59(6): 762-784, 2008. PMID: 18512708. DOI: 10.1002/art.23721

21 Bykerk VP, Akhavan P, Hazlewood GS, Schieir O, Dooley A, Haraoui B, Khraishi M, Leclercq SA, Légaré J, Mosher DP, Pencharz J, Pope JE, Thomson J, Thorne C, Zummer M, Bombardier $\mathrm{C}$ and Canadian Rheumatology Association: Canadian Rheumatology Association recommendations for pharmacological management of rheumatoid arthritis with traditional and biologic disease-modifying antirheumatic drugs. J Rheumatol 39(8): 1559-1582, 2012. PMID: 21921096. DOI: $10.3899 /$ jrheum. 110207

Received August 5, 2021 Revised September 10, 2021 Accepted September 24, 2021 